\title{
The role of Kant's Refutation of Idealism
}

\author{
(forthcoming in Archiv für Geschichte der Philosophie)
}

\author{
Ralf M. Bader \\ New York University
}

\begin{abstract}
Aвstract: This paper assesses the role of the Refutation of Idealism within the Critique of Pure Reason, as well as its relation to the treatment of idealism in the First Edition and to transcendental idealism more generally. It will be argued that the Refutation of Idealism and the Fourth Paralogism of the First Edition are consistent and that their consistence can be explained by reference to the distinction between appearances and phenomena. While the Fourth Paralogism appeals to the fact that space is a form of intuition to establish that the immediate objects of awareness, namely appearances, that are represented as being in space really are in space and classify as spatial objects, the Refutation attempts to show that at least some of these outer appearances are empirically real and have objective correlates, namely phenomena. By appealing to this distinction we can make sense of the idea that the Refutation is an extension of the Transcendental Deduction. While the Deduction, considered on its own, constitutes a 'regressive argument', the Refutation allows us to turn the Transcendental Analytic into a 'progressive argument' that proceeds by the synthetic method - the method that Kant attributed to the Critique in the Prolegomena. Accordingly, we will see that the Refutation occupies a crucial role in the Analytic. This understanding of the Refutation as attempting to establish the existence of phenomena that correspond to empirically real appearances also explains why Kant placed the Refutation of Idealism after the Second Postulate, rather than leaving it in the Transcendental Dialectic amongst the Paralogisms.
\end{abstract}




\section{Introduction}

The Refutation of Idealism is an attempt to refute what Kant calls problematic idealism. According to this kind of idealism, the existence of outer objects is doubtful and unprovable. The problematic idealist argues that our own existence and inner experience is all that we can be certain of and that the existence of the external world can only be inferred by a questionable procedure from the effects it has on us. This type of idealism is based on epistemological considerations that Kant believes to be illustrated by Descartes' methodical doubt in the Discourse on Method (cf. AA: 28, p. 68I). ${ }^{\text {I }}$

The Refutation of Idealism is an addition to the Second Edition of the Critique of Pure Reason, where it was placed amongst the Postulates of Empirical Thought. In the First Edition, it is the Fourth Paralogism in the Transcendental Dialectic that deals with problematic idealism. This account, however, was removed from the Second Edition, where it was replaced by a paralogism concerning the immateriality of the soul.

This change probably occurred due to historical reasons as Kant wanted to avoid the charge made by the Feder-Garve review in the Göttingische Anzeigen von gelehrten Sachen, published in I782, that his theory was, like that of Berkeley, a system of "idealism that encompasses spirit and matter in the same way, and transforms the world and us into representations" (Feder and Garve: 1989, p. 193). Relatedly, they had argued that his treatment of idealism in the Fourth Paralogism was unsatisfactory since "vulgar, or, as the author calls it, empirical idealism is in this way rebutted, not through a proof of the existence of bodies, but through the disappearance of the privilege, which the conviction of our own existence was thought to have" (Feder and Garve: 1989, p. 197). Kant already took up this issue in the Prolegomena, where he repeatedly tried to distance himself from Berkeleyan idealism, but obviously felt the need to further emphasise the difference. ${ }^{2}$

A further possible historical motivation can be glanced from Kant's remark in the B-Preface that it is "a scandal to philosophy and to human reason in general that the existence of things outside us ... must be accepted merely on faith" (Bxxxix). As Erdmann has noted, this is likely to be a reference to Friedrich Jacobi's criticisms of the Kantian system. Jacobi claimed that Kant's arguments were unsuccessful and that we would have to give 'faith' a systematic role in philosophy (cf. Jacobi: I785). Kant was worried by Jacobi's criticisms and used the Second Edition to reply to some of them, attempting to show that transcendental

\footnotetext{
${ }^{I}$ With the exception of references to the Critique of Pure Reason, which will take the usual form of citing the page numbers in the A- and B-editions, all references to Kant's works will be to the Akademie-Ausgabe (Kant: I900) and will be cited by giving the volume and page numbers. Translations are my own.

${ }^{2}$ Cf. AA: 4, p. 293 and the second part of the Appendix which directly addresses itself to the Feder-Garve review, AA: 4, pp. 372-380.
} 
idealism was not ineffectual and that no appeal to faith was required.

Dyck has recently argued that yet another historical motivation results from Kant's engagement with Mendelssohn's last book, the Morgenstunden, which was published in 1785 , insofar as "Kant's Refutation of Idealism is intended (at least in part) to undermine the Cartesian starting-point Mendelssohn had presumed throughout his campaign against Kantian idealism" (Dyck: manuscript). While Kant had defended the coherence of transcendental idealism against the objections raised by Mendelssohn (as well as Lambert and Schultz) in $\S 7$ of the Transcendental Aesthetic, the Refutation directly targets the Cartesian conception of self-knowledge, according to which inner intuition is privileged over outer intuition, that forms the basis of Mendelssohn's criticisms. ${ }^{3}$

In addition to these historical reasons, there were systematic reasons for changing the location of the discussion of idealism, as well as for altering the line of argument. As regards the location, we can note that it is not adequate to place a refutation of idealism in the Transcendental Dialectic among the Paralogisms. A refutation is the wrong kind of argument for this section because (i) the Dialectic consists of criticisms of dogmatic arguments, rather than of refutations of substantive positions (cf. A388-389), and (ii) the problem of idealism treated in the Refutation of Idealism is an epistemological problem, since Kant is concerned with 'problematic idealism', responding to the sceptic's epistemological challenge to the belief in the existence of the external world, and as such does not belong in the Dialectic which is concerned with metaphysical claims. Moreover, as regards the substance of the argument, it is clear that the Fourth Paralogism does not give a fully satisfactory treatment of idealism.

Accordingly, we can see that it is likely that a mixture of motivations was at play, resulting, on the one hand, from a dissatisfaction with the location and argument of the earlier refutation and, on the other, from an attempt to respond to the criticisms made by Feder, Garve, Jacobi and Mendelssohn. The problem of idealism was an important issue for Kant and was on his mind for a long time, even after having written the Refutation of Idealism. ${ }^{4} \mathrm{He}$ was not fully satisfied with his treatment of it in the Second Edition of the Critique of Pure Reason, as can be seen from the fact that he already made alterations and corrections in the B-Preface, and Kant often returned to this problem in the Reflexionen, trying out and developing new strategies to deal with it. ${ }^{5}$

\footnotetext{
${ }^{3} \mathrm{On}$ the role of Kant's anti-Cartesianism in his dispute with Lambert, Mendelssohn and Schultz, cf. Bader: forthcoming.

${ }^{4}$ In the metaphysics lectures Dohna, Kant describes idealism as "a kind of cancer in metaphysics" (AA: 28, p. 68I).

${ }^{5}$ Cf. R5653-5655, R63 I I-63 17, R6319, R6323, and the Leningrad Reflexion. The Reflexionen are Kant's hand-written notes and are collected in Volumes I4-23 of the Akademie-Ausgabe. Unlike in the case of most Reflexionen, we do know the exact dates of R63 I I-R63 I 7 and can accordingly be sure that they post-date the Second Edition since they result from Kant's discussions with Kiesewetter in September and October 1790.
} 
This paper will consider the setting of the Refutation, analysing what role it occupies within the Critique and how it is related to the Fourth Paralogism, to the Transcendental Deduction, to the Second Postulate and to transcendental idealism more generally. It will show (i) that the two refutations are not inconsistent, (ii) that the Refutation is an important extension of the Transcendental Deduction, (iii) that Kant was justified in relocating his discussion of idealism to the Postulates of Empirical Thought, and (iv) that there is no clash between transcendental idealism and the Refutation of Idealism, even though the Refutation would prove the existence of noumena, if it were to be successful.

\section{The Refutation and the Fourth Paralogism}

Traditionally, it has been argued that the Fourth Paralogism and the Refutation of Idealism are inconsistent and irreconcilable as the Refutation appears to deny what the Fourth Paralogism tried to establish. For example, Kemp Smith claims that the Refutation "proves the direct opposite of what is asserted in the first edition" and he talks about the "striking contradiction between Kant's various refutations of idealism" (Kemp Smith: 1923, p. 314). Similarly, Vaihinger says that it is impossible to find an interpretation that can reconcile the "screaming contrast" because the two refutations "relate to one another like Yes and No, like affirmation and negation, like $\mathrm{A}$ and non-A. They were, are and remain irreconcilable" (Vaihinger: I 884, pp. I 3 I-I 32 ).

This attitude is to an extent understandable since Kant says in the Fourth Paralogism that, according to transcendental idealism, matter is "only a species of representations (intuition), which are called external, not as standing in relation to objects in themselves external, but because they relate perceptions to the space in which all things are external to one another, while yet the space itself is in us" (A370). The Refutation, on the contrary, is supposed to show that timedetermination is only possible through the existence of "a thing outside me and not through the mere representation of a thing outside me" (B275).

However, here it will be argued that the two refutations are consistent. ${ }^{6}$ The difference between them can be explained insofar as they are concerned with different aspects of the idealist's challenge. The Fourth Paralogism is concerned with establishing that we are immediately aware of spatial objects, that the immediate objects of our awareness that are represented as being spatial really are spatial. Kant wants to show that we can know that there are spatial objects and that it

\footnotetext{
${ }^{6}$ The consistence of the Fourth Paralogism and the Refutation has been defended in much detail by Goldschmidt, who, however, holds not only that these arguments are consistent but also defends the claim that there is no substantive difference between them and that they differ merely in terms of the manner of presentation (cf. Goldschmidt: I 899 \& I900). Here, by contrast, it will be argued that there are important respects in which the Refutation goes beyond the Fourth Paralogism.
} 
is not the case that we have to make a problematic inference from having representations of spatial objects to the claim that there exist spatial objects which cause these representations, as he would regard any such inference to be dubious. Instead, Kant argues that spatial objects are immediately known to us and that there is consequently no need for any inference. ${ }^{7}$

In particular, the Fourth Paralogism attempts to establish that we can be immediately aware of spatial objects. It does this by arguing that that which is represented as being in space really is in space. Kant argues that transcendental idealism allows us to assert this immediacy because space is understood as a form of intuition. We are aware of appearances and appearances are subject to the forms of intuition. In particular, appearances that are subject to the form of outer intuition are in space. The outer appearances of which we are immediately aware consequently are spatial objects. This means that the reality of outer objects "need not be inferred, but is immediately perceived" (A37I). Transcendentally realist approaches, on the contrary, drive a wedge between the spatial object and the representation thereof, thereby destroying the immediacy that is required for non-inferential knowledge of the existence of spatial objects, making room for sceptical doubts.

Thus, since space is considered to be a form of intuition we can know that the immediate objects of which we are aware and that are represented as being outer really are spatial objects. Accordingly, no inference is required to establish that there are spatial entities. Yet, a corollary of the claim that space is a form of intuition is that space ends up being transcendentally ideal. As Kant notes, "the space itself is in us" (A370), which implies that different subjects have their own spatial frameworks. This means that, as far as the immediacy argument of the Fourth Paralogism is concerned, it is possible that the objects to be found in a particular subject's spatial framework may all have been produced by that subject's imagination. Put differently, the spatial objects of which we can assert the existence may turn out to be merely subjective objects. The resulting spatial world would consequently not be mind-independent even in a very weak sense and a commitment to such spatial objects would not suffice for the empirical realism that Kant wishes to defend. In other words, the Fourth Paralogism only enables us to show the existence of a spatial world but not that of an objective external world

${ }^{7}$ Two distinct arguments can be identified in the Fourth Paralogism. First, there is the immediacy argument' which holds that there is no need to make an inference to arrive at the actuality of outer objects since we are immediately conscious of them, given that space is a form of intuition (cf. A369-373). Second, there is the (rather dogmatic) argument (which is repeated in the first note following the Refutation (cf. B276-277 footnote)) that for there to be outer imagination, there must be outer perception which provides the material that can then be used by the imagination, i.e. that the imagination has no manifold of its own and can only 'invent' objects once material has been provided to it by perception (cf. A373-375). This latter argument is not discussed in this paper and all claims about the Fourth Paralogism are restricted to the former argument, which is the one that was criticised in the Feder-Garve review and that has been taken to be inconsistent with the Refutation. 
that is mind-independent and in this way fails to address the sceptical doubts of the problematic idealist. ${ }^{8}$ Showing that there is an external world in this more significant sense is the task of the Refutation of Idealism.

The Refutation does not deny the immediacy of the awareness of spatial objects, since this is a commitment that follows from Kant's arguments in the Transcendental Aesthetic, but tries to go beyond the Fourth Paralogism by showing that at least some of the spatial objects of which we are aware are empirically real, which is to say that there is a significant sense in which this kind of object classifies as being mind-independent and accordingly counts as 'a thing outside me' and not as a 'mere representation of a thing outside me'.

Thus, to make sense of the Refutation we need to distinguish between different kinds of appearances, between different kinds of spatial objects of which we are aware. In this way one can accept the upshots of the Transcendental Aesthetic that Kant highlights in the Fourth Paralogism, namely that we are immediately aware of spatial objects and do not need to infer their existence, but still argue that there is work to be done by the Refutation if the sceptic's challenge is to be met, namely to establish that at least some outer appearances are empirically real since they are the result of empirical intuition rather than imagination. ${ }^{9}$

In particular, we need to distinguish between appearances that have objective correlates and appearances that lack such correlates. The former appearances are empirically real and are known to us by the receptivity of outer sense, while the latter are empirically ideal and are the result of the spontaneity of the imagination (cf. AA: 28, pp. 680-68I). ${ }^{\text {Io }}$ Both empirically real and empirically ideal appearances are empirically outer in that they are spatial, but only the former are external in the sense of being mind-independent as a result of having correlates that are distinct from the subject. ${ }^{\text {II }}$ If an appearance is empirically real, then the object of

\footnotetext{
${ }^{8}$ Given the transcendental ideality of space and time, the relevant notion of mindindependence is restricted in that it applies only to the matter and not to the form of this external world.

${ }^{9}$ Which appearances are empirically real is something that the Refutation does not establish. "Here it had to be proved only that inner experience in general is possible only through outer experience in general. Whether this or that putative experience is not mere imagination must be ascertained according to its particular determinations and through its coherence with the criteria of all actual experience" (B278-279).

${ }^{10}$ This distinction corresponds to that between appearances in the transcendental sense and appearances in the empirical sense (cf. AA: 20, p. 269).

${ }^{\text {II }} \mathrm{Cf}$. "[T] $\mathrm{T}$ he permanent with respect to which [representations] are determined as successive has to be outside them in the stronger sense outlined in the fourth Paralogism in A: in the sense of being distinct from them, ontologically independent of them" (Longuenesse: 2008, p. 29).

Emundts objects to this ontological approach, arguing that "we do not need to refer to ontologically distinct things. Instead, we must consider the ground for the objectivity of representations." (cf. Emundts: 20I0, p. I8I) Appealing to the conditions of objectivity that are provided by the analogies of experience is taken by her to be sufficient to distinguish things from mere representations. This suggestion, however, faces the problem that we cannot appeal to these principles since their applicability is precisely what is at issue. Emundts seems to ignore Kant's claim that idealism
} 
which a subject is aware and which is located in that subject's spatial framework corresponds to a phenomenon that is located in objective space. ${ }^{\mathrm{I2}}$ The content of the spatial framework is only empirically real insofar as it is not the product of the imagination but results from outer intuition. Such objective content is not dependent on particularities of the subject, but is produced by the interaction between the form of intuition and the manifold of intuition provided by noumenal affection. Appearances that are empirically ideal, by contrast, do not result from outer intuition but are merely subjective products of the imagination. As a result, they do not have objective correlates, which means that no phenomena correspond to them.

The idealist's epistemological challenge arises from the difficulty of distinguishing outer intuition from imagination. Appearances produced by these two different sources are introspectively indistinguishable. The differences between them derive only from their origin and regard their status but not their determinations. There is nothing inherent in an outer appearance that tells us the origin of that appearance and consequently any inference regarding this origin is uncertain. The sceptic then claims that, as a result of this predicament, we can only attempt to prove the existence of outer objects mediately.

Thus, the difference between empirically real and empirically ideal appearances cannot be identified by their determinations as they are introspectively indistinguishable. Instead, one has to examine what their source or ground of existence is since they differ as regards their ontological status and their causal origin (cf. AA: 28, p. 77I). While the existence of empirically ideal appearances is due to our imagination, that of empirically real appearances is due to noumenal affection which means that they owe their existence to something that is external and distinct from us. The problem then is to find some way of showing that appearances that have a particular ontological status are required. This precisely is what Kant wants to do by showing that empirically real appearances are needed for making empirical self-consciousness possible, thereby establishing that " $[\mathrm{t}] \mathrm{he}$ mere, but empirically determined, consciousness of my own existence proves the existence of objects in space outside me" (B275). Otherwise, as long as one focuses only on the determinations of appearances, the sceptical possibility that all

raises a 'serious objection' (B274) to the applicability of these principles. Kant appears to think that we need to refute idealism in order to be able to apply them, rather than it being possible to refute idealism by appealing to them, as would be required by Emundt's account. (It is also for this reason that we have to reject the view put forward by Abela, and endorsed by Emundts, that the Refutation does not go beyond the Analogies (cf. Emundts: 20I0, p. I 82 footnote 24).)

${ }^{\text {I2 } T h e ~ d i s t i n c t i o n ~ b e t w e e n ~ a p p e a r a n c e s ~ a n d ~ p h e n o m e n a ~ p u t ~ f o r w a r d ~ i n ~ t h i s ~ p a p e r ~ c o r r e s p o n d s ~}$

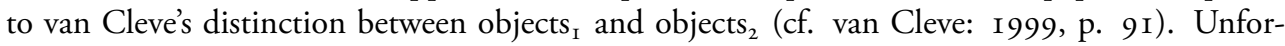
tunately, Kant does not consistently distinguish phenomena from appearances and our usage of these terms is accordingly largely stipulative, though there is clear evidence to the effect that he had such a distinction in mind, cf. AI 89-I 90/B234-235 and compare A20/B 34 with A248-249.

A closely related distinction is that between judgements of perception, which are subjectively valid, and judgements of experience, which are objectively valid (cf. 4:298-299). 
outer appearances could turn out to be empirically ideal remains.

Accordingly, Kant wants to prove in the Refutation "that we have experience, and not merely imagination of outer things" (B275). This is the problem that was not answered by the First Edition refutation. The first refutation only succeeded in proving the immediacy of our awareness of outer appearances, irrespective of their origin. Kant had argued in the Fourth Paralogism that all spatial appearances really are in space and are immediately known to the subject. Yet, only those that have objective correlates are empirically real. It is the existence of these empirically real appearances and of their corresponding phenomena that Kant attempts to prove in the Refutation of Idealism. The second refutation is thus meant to establish that outer appearances are not only immediate objects of awareness, but that we can know that at least some of the outer appearances of which we are aware have objective correlates. This would establish that the apparent possibility that all our outer appearances are mere products of the imagination and that there are no empirically real objects corresponding to them is in fact not a real possibility. The two refutations thus turn out to be consistent.

\section{The Refutation and the Transcendental Deduction}

This account of what the Refutation attempts to achieve integrates well with an understanding of the Transcendental Deduction as a 'regressive argument' and allows us to consider the Refutation as an extension of the Deduction.

According to Ameriks's interpretation of the Deduction, Kant is making a 'regressive argument', that is, an argument that identifies the conditions of something that is assumed or taken for granted, rather than a progressive argument that identifies the conditions of something that is known or the objectivity of which has been demonstrated and which would accordingly allow for the inference to the actuality of the conditions. In particular, it starts with a 'thick' conception of experience and attempts to establish the necessary preconditions of this kind of experience. ${ }^{\mathrm{I3}}$

Unlike the re-constructions of interpreters such as Bennett and Strawson, this approach does not see the Deduction as an anti-sceptical argument that attempts to establish the objectivity of experience from something like the mere fact that we are self-conscious. Such accounts are problematic in that the Deduction is not based on empirical apperception but on the original or objective unity of apperception. Accordingly, it is not an argument against Cartesian scepticism, but is only concerned with a form of scepticism that is concerned with "claims of the higher faculty of reason" (Ameriks: 2003, p. I I). That we do have empirical knowledge is not questioned, but simply taken for granted. What is questioned is

\footnotetext{
${ }^{13}$ For textual support and defence of the idea that experience has to be understood in a thick sense, cf. Engstrom: 1994, p. 363.
} 
how reason can give rise to synthetic a priori knowledge. Showing how pure concepts can be in necessary agreement with experience and can give rise to synthetic a priori principles is what the Deduction is meant to establish according to the regressive reading. The scepticism that is addressed is thus not a Cartesian form of scepticism about the external world, but a Humean scepticism about reason (cf. AA: 5, p. 52 and Engstrom: 1994).

According to the regressive strategy interpretation, the Deduction establishes the conditional that if the assumption that we do have experience in the 'thick' sense is justified, then it follows that the necessary preconditions of the possibility of experience are actually met. Put differently, the Deduction establishes what the presuppositions of the possibility of experience are and shows that the categories apply a priori to objects of a possible experience and are thus objectively valid. On this interpretation, one should "understand the deduction as moving from the assumption that there is empirical knowledge to a proof of the preconditions of that knowledge" (Ameriks: 2003, p. 5I).

An important upshot of this interpretation is that the substantive nature of the assumption on which the Deduction is based ensures that it is not evident that this assumption is actually met, thereby making it susceptible to sceptical doubts. As a result, there is a close connection between the starting-point of the Deduction and the conclusion of the Refutation. Insofar as the Refutation attempts to prove the actuality of outer experience and thereby the existence of empirically real appearances that have objective correlates, it can be understood as attempting to show that we can know that the kinds of objects to which the categories are applicable do exist. Thus, while the Deduction establishes the conditional 'if we do have experience, then the categories are objectively valid', the Refutation can be seen to establish the actuality of the antecedent, namely that we do have experience in the 'thick' sense that is required by the Deduction, i.e. objective experience of the phenomenal realm.

We can thus consider the Refutation as an extension of the Deduction since it alters the status of the conclusion of the Transcendental Deduction when the two are combined. Kant will no longer merely have established the problematic conditional connecting experience, understood in a thick sense, with the objective validity of the categories, but will have supported the required premise to make an inference from this problematic conditional to the actuality of the consequent. The Refutation thus changes the Deduction from a regressive to a progressive argument since by means of it we can assert the antecedent of the conditional. The categories in this way turn out to be indirectly the necessary presuppositions of the possibility of inner experience. This is because the objective validity of the categories is a necessary condition of the possibility of outer experience (as argued in the Deduction) and because outer experience is a necessary condition of the possibility of inner experience (as argued in the Refutation). Accordingly, if it is known that we do have inner experience, then this implies that all the necessary 
presuppositions are actual.

The Refutation thus extends and complements the Deduction because the Refutation itself is a progressive argument and because the consequent of the Refutation implies the antecedent of the Deduction. The Refutation is a progressive argument that starts from a premise that is supposedly accepted even by the problematic idealist, namely knowledge of one's existence as determined in time. ${ }^{14}$ By identifying the preconditions of something which we know to obtain, we can progress from that something and assert the actuality of its necessary presuppositions. This, after all, is what makes it a refutation, rather than a deduction.

Ameriks has tried to argue that the Refutation is not progressive but regressive. He sees Kant as starting with the assumption that we do have empirical knowledge of our inner states and then arguing for the necessary presuppositions regarding outer experience that must be met for this to be possible, rather than being involved in an anti-sceptical argument that establishes the existence of outer objects. While Ameriks is right in pointing out that Kant is not directly concerned with establishing externality in the transcendental sense, we have to take seriously the claim that what Kant wants to do is to establish the reality of things, and not merely of representations (cf. B275). In other words, he wants to establish the existence of phenomena and in doing this he does establish the existence of things in themselves since they function as the grounds of the objective correlates of empirically real appearances (cf. section 5 below).

Though "the Refutation has to do merely with empirical externality" (Ameriks: 2006, p. 74), this externality is the externality of things, i.e. of phenomena that correspond to empirically real appearances, and not that of mere representations. It is an externality that goes beyond the externality of the Fourth Paralogism, i.e. merely being represented as being external, and hence requires us to bring in things in themselves, even though that is not the direct aim of the Refutation. The externality that Kant wants to establish is not exhausted by spatiality. Instead, it goes beyond the determination of the object as spatial and concerns the question whether an independent existent corresponds to the spatial appearance. This requires an understanding of externality as involving mind-independence

\footnotetext{
${ }^{14}$ While the target of the Refutation is identified with the problematic idealism of Descartes, and while its starting-point is meant to correspond to the one empirical assertion that Descartes considered to be indubitable, namely cognition of one's existence (cf. B274 and B277), it seems that in order for the Refutation to have any chance of being successful, it would have to proceed from a relatively substantive starting-point by taking a thick understanding of inner experience for granted, thereby opening it up to sceptical doubts. This would be unproblematic if Kant should merely be concerned with refuting those who base their scepticism or idealism on a supposed asymmetry between inner and outer sense and accordingly restrict their doubts to outer objects in a way that exempts inner experience from their sceptical scruples. Yet, it would cause problems for any attempt to refute a version of scepticism that challenges all of 'experience' that is not indubitable, which would imply that the Refutation would fall short of refuting hyperbolic doubt (though it would still make progress towards establishing 'experience' and thus still complement the Deduction).
} 
and hence distinctness from the subject. Mere empirical or spatial distinctness is not sufficient for the object to have the status of an independent objective entity. Rather, in order for it to be mind-independent, it must have a ground that is transcendentally distinct, it must be grounded in a noumenal object.

Thus, we can see that the Refutation is a progressive argument that allows us to assert the antecedent of the conditional established by the Deduction. Yet, this does not mean that the Deduction is dependent on the Refutation and that it would be incomplete without it. The Deduction would only be incomplete and in need of supplementation by the Refutation if it were intended as an anti-sceptical argument. However, as Ameriks and Engstrom have convincingly argued, this is not the case. Kant is not attempting to refute scepticism in the Deduction. Pace Ameriks, this is the task of the Refutation.

In order to make sense of the relation between the Refutation and the Transcendental Deduction we need to combine regressive and progressive arguments. Those, on the one hand, who consider the Transcendental Deduction as an antisceptical rather than as a regressive argument face the problem of explaining why there is a need for the Refutation since the sceptic has supposedly already been dealt with in the Deduction. Those, on the other, who consider both the Transcendental Deduction and the Refutation as being regressive arguments also face the problem of explaining why there is a need for the Refutation since this time the sceptic is neither targeted in the Deduction nor in the Refutation. In both cases, interpreters have difficulty in explaining what the Refutation adds to the Deduction. These problems can be avoided by giving a regressive interpretation of the Deduction and a progressive interpretation of the Refutation.

If this analysis is correct, then the Refutation turns out to be quite crucial for the Transcendental Analytic as it will be due to it that we can turn the regressive arguments into progressive arguments and thereby fulfil the task of the Analytic as a progressive argument that proceeds by means of the synthetic method. In other words, the combination of the Refutation and the Deduction constitutes a progressive argument that establishes the objective validity of the categories as well as the existence of empirically real appearances that have objective correlates. This would make the Transcendental Analytic, considered as a whole, a progressive argument as Kant announced in $\S \S 4-5$ of the Prolegomena.

In October 1794 Friedrich von Herbert wrote a letter to J. B. Erhard saying that "Kant's entire system can be expressed in the hypothetical proposition, 'If experience is ...then'. That experience is, is thereby presupposed, postulated, or however one calls it. Now if a skeptic were dumb and shameless enough to say, 'But is there experience?' there is really no answer." While this seems to be an adequate characterisation of the Transcendental Analytic as it appears in the First Edition, the situation is changed in the Second Edition since the Refutation is an argument that attempts to answer the sceptic by establishing that there is 
experience and thereby tries to complete the Analytic.

This account of the relation between the Refutation and the Deduction has the consequence that the First Edition is in an important sense incomplete insofar as it simply takes for granted that there is 'experience', which conflicts with Kant's characterisation of the First Edition as following the synthetic method. One explanation for the changes from the First Edition to the Second Edition is that, whilst reworking the Deduction, Kant came to realise the substantive nature of its starting-point and its consequent susceptibility to sceptical doubts. As Kant notes in the Metaphysical Foundations of Natural Science, the question of how experience is possible through the categories "can almost be accomplished through a single inference from the precisely determined definition of a judgment in general" (4:476 footnote). Since the notion of judgement that is at issue corresponds to that of a judgement of experience, rather than a mere judgement of perception, and is characterised in $\S 19$ of the B-Deduction as the bringing of given cognitions to the the objective, rather than merely empirical, unity of apperception, the substantive nature of the starting-point of the Deduction comes to the fore. Once it is realised that the Deduction is based on the notion of an objectively valid judgement, the need to establish that we have experience and that (some of) our judgements are judgements of experience that are objectively valid becomes pressing and calls for a refutation of idealism, a task that has not been properly addressed by the Fourth Paralogism, given that it largely amounts to an elaborate restatement of claims that had been established in the Transcendental Aesthetic.

The view that Kant simply assumed experience to be given is sometimes called the 'fact of experience' ('Faktum der Erfahrung'), paralleling the 'fact of reason' which Kant identifies in the Critique of Practical Reason. ${ }^{\text {Is }}$ We can take this parallel further by comparing the Transcendental Deduction in the Critique of Pure Reason with the Deduction of the categorical imperative in Section III of the Groundwork. The Transcendental Deduction shows that the categories are necessary presuppositions for the possibility of experience, while Section III of the Groundwork shows that freedom is a necessary presupposition for the possibility of morality, it is its ratio essendi as Kant states in the Critique of Practical Reason (cf. AA: 5, p. 4 footnote). ${ }^{16}$ The Refutation establishes the actuality of experience and thereby the objective validity of the categories, while the 'fact of reason' provides us with evidence for the actuality of morality and thereby warrants our belief that we possess transcendental freedom, making morality the ratio cognoscendi of

${ }^{\text {Is }}$ This view played an important role in criticisms of the Kantian system raised by Salomon Maimon in his 1790 Versuch über die Transcendentalphilosophie and by Karl Leonhard Reinhold in his Beyträge zur Berichtigung bisheriger Missverständnisse der Philosophen, also published in 1790.

${ }^{16}$ This presupposes that we can give a regressive strategy interpretation of the deduction in the Groundwork, something that, prima facie, seems to be at odds with what Kant says in the Preface (cf. AA: 4, p. 392), yet plausible regressive interpretations of the Groundwork as a whole have been put forward (cf. Schönecker: 1996 and Brandt: 1988). 
freedom (cf. AA: 5, p. 4 footnote). ${ }^{17}$

The epistemological force of the Refutation is stronger since, if it were successful, it would allow us to go beyond the 'fact of experience' and establish the actuality of experience, thereby refuting the problematic idealist. There is no equivalent in the moral sphere that enables us to go beyond the 'fact of reason'. We are not able to establish with certainty the actuality of morality and thus cannot refute the sceptic about morality. This cannot be achieved in the Critical system since it would allow us to deduce the actuality of freedom, something that is ruled out by transcendental idealism. We only have a belief that we are free that is warranted by practical reason, but we cannot gain any knowledge in this regard. It is this difference in epistemological force between the Refutation and the 'fact of reason' that underwrites the difference between the theoretico-dogmatic method that is warranted by the former and the practico-dogmatic method supported by the latter. ${ }^{18}$ In the one case, the employment of the dogmatic method is justified by theoretical considerations and consequently provides us with knowledge. In the other case, it is justified by practical considerations and hence provides us not with knowledge but only with beliefs that are warranted from a practical point of view.

\section{The Refutation and the Second Postulate}

It is clear that a refutation of idealism should not feature as the Fourth Paralogism in the Transcendental Dialectic. It is not adequate to place a refutation in the Dialectic since the task of this part of the Critique is to criticise mistaken dogmatic arguments, rather than to provide positive arguments for any particular thesis. In Kantian terminology, the Refutation of Idealism does not classify as a 'critical objection' but instead as a 'dogmatic objection' since it is directed against a proposition rather than against a proof (cf. A388-389).

A refutation of idealism should not just criticise sceptical arguments, but provide positive support for the belief in the existence of the external world and should thus be part of the Transcendental Analytic. Arguments in the Dialectic do not establish the falsity of a thesis, but only the falsity of dogmatic arguments and consequently lead to agnosticism rather than justifying any substantive beliefs. They show us that reason oversteps its boundaries in trying to establish the propositions put forward by the dogmatic rationalists and thereby show us what we cannot establish by means of reason. Whether or not the views held made by

\footnotetext{
${ }^{17}$ Rather than having to endorse a variant of the 'great reversal' interpretation (cf. Ameriks: 2000 , p. 226), this would allow us to consider Section III of the Groundwork and the 'fact of reason' as jointly constituting a two-step argument, laying the foundations for the Metaphysics of Morals.

${ }^{18}$ Kant develops the distinction between the theoretico- and practico-dogmatic methods in his I79 I Preisschrift über die Vortschritte der Metaphysik.
} 
the dogmatic philosophers are actually correct is a different matter.

Moreover, the Dialectic is concerned with the metaphysical claims of the dogmatists. Accordingly, it is not fitting to discuss the epistemological problem of idealism in the Dialectic. The rational psychologists misuse the 'I' of transcendental apperception to arrive at positive metaphysical conclusions. In particular, they attempt to demonstrate the immateriality and immortality of the soul. The task of the Paralogisms is to identify the errors involved in these dogmatic arguments and show how they result from a transcendental illusion. Cartesian scepticism regarding the external world does not belong amongst these arguments since it poses an epistemological challenge to our beliefs, rather than constituting a subreptive metaphysical argument that is based on an unavoidable illusion. Kant's replacement for the Fourth Paralogism, namely the discussion of the metaphysical claim that a being "could exist merely as thinking being" (B409) in the B-Edition, is much better suited for the Paralogisms.

Thus, we can see that there are good reasons for being dissatisfied with a treatment of idealism in the Dialectic, since a refutation of idealism is a positive argument against epistemological scepticism and not a criticism that shows the metaphysical arguments of dogmatists to be mistaken and to be based on a transcendental illusion. However, where exactly it should be placed in the Analytic is a further question. In order to justify Kant's relocation we have to not only give reasons why it should no longer be in the Dialectic, but must give positive reasons for placing it after the Second Postulate. Here we can appeal to the distinction between empirically real and empirically ideal appearances and to our previous discussion of the relation between the Refutation and the Deduction to explain why Kant chose to relocate his refutation of idealism from the Paralogisms to the Postulates.

Strawson claims that the Refutation is "not very strategically placed in the middle of the Postulates of Empirical Thought" (Strawson: 1966, p. I22). Similarly, Bennett claims that Kant's reason for changing the position of the Refutation is "silly" (Bennett: I 966, p. I 66). Such comments are not adequate as there are good reasons for placing the Refutation exactly where Kant chose to place it.

Occasionally commentators simply state that the Second Postulate is concerned with what is actual and that Kant wants to show in the Refutation that external objects are actual (cf. Guyer and Wood: I998, p. 7 I and Okochi: 2005, p. 45). While this is correct, there is more to be said and one ought to take seriously what he himself says, namely that idealism raises a serious objection to the arguments of the Second Postulate, insofar as it poses "what is a serious objection to these rules for proving existence mediately" (B274). ${ }^{19}$

\footnotetext{
${ }^{19}$ Sellars accepts that the relocation makes sense, arguing that " $[\mathrm{t}]$ he relation of our knowledge of material things to our perceptual experiences is far more at home in a section devoted to the thesis that 'that which is bound up with the material conditions of experience, that is, with sen-
} 
First, we can note that the distinction between empirically real and empirically ideal appearances helps us to explain the location of the Refutation in the Second Edition. In particular, it makes sense to locate it in the System of Principles since there is a problem with the Principles insofar as they only apply to 'experience', understood in a thick sense, and not to representations produced by the imagination. Consequently, the Principles would be inapplicable if idealism were true. As Kant notes in the case of the Second Postulate, "[i]f we do not begin with experience ..., then we are only making a vain display of wanting to discover or research the existence of any thing" (A226/B273-274, italics added). ${ }^{20}$ To determine something as actual, to determine something as existing at a determinate moment in time, one needs to start out with experience and not with imagination. The same applies to all the other categories since they are equally concerned with the necessary presuppositions of experience. That we do have experience, in the thick sense in which Kant uses this notion, is in no way given. Though the categories would still be necessary presuppositions of the possibility of experience if idealism were to be true, there would not be any objects to which they would be applicable, making it the case that the categories would accordingly lack objective reality.

The Refutation is thus placed amongst the Principles because the Principles only apply to appearances that have objective correlates since only these appearances are produced by outer intuition and are part of 'experience'. Put differently,

sation, is actual.' For this bound-up-ness, when one spells it out does have an inferential aspect and therefore does lead naturally to the Cartesian problem" (Sellars: i974, p. I66).

However, though there is a Cartesian problem, it is to be found elsewhere. It is not that that which is bound up with sensation is subject to the Cartesian problem, i.e. that one has to make a problematic inference from sensation to its causes. This particular inferential aspect is not problematic given the apodeictic certainty of the law of causality. Instead, the problem lies in identifying that one is concerned with 'experience', i.e. in establishing that the apodeictic law of causality does indeed apply. The problematic inferential aspect thus enters the picture insofar as one must infer from having representations that these are representations produced by intuition rather than imagination. The awareness of appearances would have to warrant an inference to the claim that some of the appearances are empirically real and have objective correlates. Put differently, the idealist only challenges the premise underlying the application of these rules. $\mathrm{He}$ can accept that the rules can be applied if we have experience, but then questions whether they can in fact be applied to the appearances of which we are aware, since it is not certain whether the condition that we have experience is actually met. All that the idealist has to doubt is that we can know that we actually have outer intuitions, proposing instead the possibility that that which we take to be the product of outer intuition is actually produced by the imagination. In this way the problematic idealist issues an epistemological challenge by questioning whether we can have knowledge that there are in fact any objects to which these rules apply. If the Refutation were successful, the problematic inferential move from representation to intuition could be avoided insofar as we would then know that we are aware of empirically real appearances and that we do have outer intuitions and not merely outer imaginations.

${ }^{20} \mathrm{Cf}$. "Herewith the foundation of the postulate, that asserts the reality of perceived objects and above all of objects established according to a priori rules of experience, would be removed" (Brandt: 1987 , p. 9). 
only empirically real appearances are subject to the Principles, which means that they would not be of any significance if all objects of awareness were mere appearances that would lack objective correlates and would hence be empirically ideal. Consequently, the regressive argument of the Deduction must be turned into a progressive argument if the Principles are to be applicable and if the categories are to have objective reality. Accordingly, we can see that our interpretation of the relation between the Deduction and Refutation fits in nicely with the explanation that Kant gives for his relocation of his treatment of idealism.

Second, it should be noted that while all of the categories are dependent on experience in this way, the Postulates stand in a special relation to idealism. This is because the question of idealism does not pertain to the determinations of objects but to their ontological status and is accordingly related to the Postulates in that they concern the modal categories which "have the peculiarity that, as a determination of the object, they do not in the least augment the concept to which they are ascribed, but rather express only the relation to the faculty of cognition" (A219/B266).

Third, we can see that the Refutation is appropriately placed after the Second Postulate in particular. To begin with, as noted above, this postulate is concerned with actuality and what Kant attempts to do in the Refutation is to prove that outer objects do exist, which is to say that they are actual. Moreover, the schema of actuality is "existence at a determinate time" (AI45/BI84) which relates to the argument put forward in the Refutation insofar as it appeals to the conditions for determining one's existence in time. Furthermore, since this postulate is concerned with the material conditions of experience insofar as it holds that everything is actual that is connected according to the categories of relation with some actual perception (cf. A225/B272), it requires that something be given in perception rather than merely imagined. If nothing were to be given in perception, but if instead everything were to be a product of the imagination, then this Postulate would become irrelevant. The First Postulate, by contrast, is concerned with the formal conditions of experience and is thus not directly dependent on perception. Since the Third Postulate is concerned with the general conditions of experience insofar as they determine the relations amongst that which is actual, its applicability is dependent on the Second Postulate, making it dependent on perception at one remove. Accordingly, we can see that it is the Second Postulate that is directly threatened by problematic idealism.

\section{The Refutation and the noumenal sphere}

Thus, we have seen that the Refutation is an attempt to prove the existence of phenomena. This implies that the Refutation of Idealism, if it were to be successful, would actually prove the existence of things in themselves. In particular, if it were to succeed, the Refutation would establish the existence of phenomena 
and we would then be licensed to infer from this the existence of noumena, given that transcendental idealism requires that phenomena be grounded in noumena. This is because it is only by reference to things in themselves that we can make sense of the permanent existence of external objects that are independent of us. ${ }^{21}$ The kind of mind-independence that is required for there to be empirically real external objects can only be grounded in the noumenal sphere. As Kant notes in his controversy with Eberhard, "the objective grounds, namely the things in themselves, are not in space and time, but in that which the Critique calls their extra- or super-sensible substrate (noumenon)" (8:207). Thus, showing that there are appearances that have not been produced by the imagination but result from outer intuition and to which the categories are applicable is tantamount to showing that there are noumena.

Kant explicitly states this in some of the later Reflexionen, particularly in R5984, R63I2, R63I7 and R6323. "Thus the ground of the possibility of the latter [i.e. the possibility of the temporal determination of my existence in time] must lie in the relation of the representation to something outside us, more precisely something that is itself not again mere inner representation, i.e. form of the appearance, and consequently thing in itself” (AA: I 8, p. 6I 2, R63 I 2). Similarly, Kant talks about the need for something outer "that not merely exists in my representation (but (as thing) in itself)" (AA: I8, p. 643, R6323).

While the Refutation would prove the existence of noumena, this is not in conflict with the epistemic strictures of transcendental idealism That we know that noumena exist (although we do not know them) does not violate critical principles, as these noumena are completely indeterminate for us. We lack knowledge of any of their positive determinations and can only consider them as whatever it is that grounds phenomena. The Refutation only underwrites the limited claim that there are noumena that ground phenomena, but it does not allow us to attribute any positive determinations to them.

Guyer argues that the Refutation cannot prove the existence of noumena as they are inaccessible to our knowledge (cf. Guyer: 1987, p. 282). His argument, however, is based on the mistaken assumption that the external objects are to be equated with noumena. ${ }^{22}$ This assumption is misguided since noumena

\footnotetext{
${ }^{21}$ Without bringing in things in themselves, it would not be possible to respond to Guyer's charge that "in spite of the stress Kant places on the contrast between a 'thing outside me' and a 'mere representation,' it is not obvious what this contrast means. Thus, exactly what thesis the refutation is supposed to prove is unclear" (Guyer: 1987, p. 280).

${ }^{22}$ This mistake has a long history going back to the first reviews of the Second Edition of the Critique. It can be found, for instance, in H. A. Pistorius' review in the Allgemeine deutsche Bibliothek (cf. Pistorius: I788, p. 349).

This misguided assumption also underlies other objections against interpreting Kant as invoking transcendentally distinct objects in making the distinction between things and mere representations, such as the one put forward by Emundts to the effect that "[i]f he were talking about the thing in itself as that whose affection causes a representation, then he would have to claim that the thing in itself has to be conceived as persistent" (Emundts: 20I0, p. I80). While such
} 
are only needed to explain the possibility of external objects, rather than being identified with these objects. In other words, noumena constitute the ground of externality, which means that without noumena there could not be any external and empirically real objects. ${ }^{23}$

The proof of the existence of noumena is consequently a transcendental proof, insofar as the existence of noumena is a necessary presupposition for the possibility of externality, and externality, in turn, is a necessary presupposition for the possibility of experience. The existence of noumena is thus a necessary presupposition for a necessary presupposition for the possibility of experience. Accordingly, it is a mediate rather than an immediate transcendental proof.

\section{Conclusion}

Thus, we can see that the Refutation of Idealism is consistent with the Fourth Paralogism. While the Fourth Paralogism is concerned with showing that we can be immediately aware of outer appearances and that such appearances are in space, the Refutation tries to establish that there exist phenomena, that some outer appearances are empirically real and have objective correlates, thereby refuting the epistemological challenge of the problematic idealist. Kant attempts to show that the apparent possibility that all appearances are products of the imagination rather than resulting from intuition is not a real possibility. If the sceptical scenario depicted by the idealist were to be true, the Postulates, as well as the other synthetic a priori principles of pure understanding, would be inapplicable and the categories would lack objective reality. Accordingly, we can understand why Kant relocated his discussion of idealism, trying to repudiate the idealistic challenge to the applicability of the Second Postulate. On this understanding, the Refutation occupies a crucial role in the Analytic, turning the regressive argument of the Deduction into a progressive argument. After having shown that the categories are necessary presuppositions of the possibility of experience and that experience is governed by various synthetic a priori principles of pure understanding, in the Refutation Kant attempts to establish that we actually have experience of external objects. He tries to achieve this by starting from the indubitable fact that we have self-knowledge, that is, that we are conscious of ourselves as existing in time. This starting-point is supposedly even accepted by the Cartesian sceptic who is motivated by the methodical doubt. He then wants to demonstrate that the ex-

objections are telling against those construals that identify the thing in itself with the "thing outside me", they do not affect the interpretation developed in this paper which distinguishes the transcendentally distinct atemporal ground from the objective persistent phenomenon.

${ }^{23}$ This kind of view might appear to be problematic insofar as it would seem to be subject to problems of double-affection. For an account of transcendental idealism that allows us to make sense of the idea that noumena ground phenomena whilst avoiding a commitment to a theory of double-affection, cf. Bader: 20 Io. 
istence of external objects is a necessary presupposition for the possibility of such self-knowledge, thereby refuting problematic idealism. ${ }^{24}$

${ }^{24}$ For helpful comments and discussions, I would like to thank Karl Ameriks, Andrea Christofidou, Corey Dyck, Colin Marshall, Tyke Nunez, two anonymous referees and an audience at a UK Kant Society conference. 


\section{References}

[I] Ameriks, K. Kant's Theory of Mind, 2nd ed. Oxford University Press, 2000.

[2] Ameriks, K. Interpreting Kant's Critiques. Oxford University Press, 2003.

[3] Amerixs, K. Kant and the Historical Turn: Philosophy as Critical Interpretation. Oxford University Press, 2006.

[4] Bader, R. M. The Transcendental Structure of the World. PhD thesis, University of St Andrews, 20 Io.

[5] BADER, R. M. Self-Knowledge in $\S 7$ of the Transcendental Aesthetic. In Proceedings of the XI ${ }^{\text {h }}$ International Kant Kongress, S. Bacin, Ed. de Gruyter, forthcoming.

[6] Bennett, J. Kant's Analytic. Cambridge University Press, I 966.

[7] Brandt, R. Einleitung zu 'Eine neu aufgefundene Reflexion Kants "Vom inneren Sinne" (Loses Blatt Leningrad I)'. In Neue Autographen und Dokumente zu Kants Leben, Schriften und Vorlesungen, R. Brandt and W. Stark, Eds. Felix Meiner Verlag, I987, pp. I-I7.

[8] Brandt, R. Der Zirkel im dritten Abschnitt von Kants Grundlegung zur Metaphysik der Sitten. In Kant. Analyen - Probleme - Kritik, H. Oberer and G. Seel, Eds. Königshausen und Neumann, I989.

[9] Dyck, C. Turning the Game against the Idealist: Mendelssohn's Refutation of Idealism in the Morgenstunden and Kant's Replies. Manuscript.

[io] Emundts, D. The Refutation of Idealism and the Distinction between Phenomena and Noumena. In The Cambridge Companion to Kant's 'Critique of Pure Reason', P. Guyer, Ed. Cambridge University Press, 2010, pp. I68-I89.

[i i] Engstrom, S. The Transcendental Deduction and Skepticism. Journal of the History of Philosophy 32, 3 (1994), 359-380.

[i 2] Feder, J., And Garve, C. Die Göttinger Rezension. In Prolegomena zu einer jeden künftigen Metaphysik, die als Wissenschaft wird auftreten können, R. Malter, Ed. Reclam, I989, pp. 192-200.

[i 3] Goldschmidt, L. Kants 'Widerlegung des Idealismus' I. Archiv für systematische Philosophie 5 (1899), 420-453.

[i 4] Goldschmidt, L. Kants 'Widerlegung des Idealismus' II. Archiv für systematische Philosophie 6 (I 900), 28-63. 
[1 5] Guyer, P. Kant and the Claims of Knowledge. Cambridge University Press, 1987.

[16] Guyer, P., And Wood, A. Introduction. In Critique of Pure Reason. Cambridge University Press, I998, pp. I-80.

[I7] Jасові, F. H. David Hume über den Glauben, oder Idealismus und Realismus, ein Gespräch. Löwe, 1785.

[I 8] Kant, I. Kants gesammelte Schriften. Reimer/de Gruyter, I 900.

[19] Kant, I. Vom inneren Sinne (Loses Blatt Leningrad I). In Neue Autographen und Dokumente zu Kants Leben, Schriften und Vorlesungen, R. Brandt and W. Stark, Eds. Felix Meiner Verlag, I987, pp. I 8-2 I.

[20] Kemp Smith, N. A Commentary to Kant's 'Critique of Pure Reason', 2nd, revised and enlarged ed. Macmillan, I923.

[2 I] Longuenesse, B. Kant's 'I Think' and Descartes' 'I Am a Thing That Thinks'. In Kant and the Early Moderns, D. Garber and B. Longuenesse, Eds. Princeton University Press, 2008, pp. 9-3 I.

[22] Maimon, S. Versuch über die Transcendentalphilosophie. Voss und Sohn, I790.

[23] Окосні, T. Der Transzendentale Idealismus und die Widerlegung des Materialen Idealismus in den Beiden Auflagen der Kritik der Reinen Vernunft und den Prolegomena von Kant. Hitotsubashi Journal of Social Studies 37 (2005), 33-5I.

[24] Pistorius, H. A. Critik der reinen Vernunft von Immanuel Kant, Prof. in Königsberg, der Königl. Akademie der Wissenschaften in Berlin Mitglied. Zweyte hin und wieder verbesserte Auflage. Allgemeine deutsche Bibliothek $8 I, 2$ (I788), 343-354.

[25] Reinhold, K. L. Beyträge zur Berichtingung bisheriger Missverständnisse der Philosophen. Erster Band das Fundament der Elementarphilosophie betreffend. Johann Michael Mauke, I790.

[26] Sснӧnecker, D. Zur Analytizität der Grundlegung. Kant-Studien 87 (I996), 348-354.

[27] Sellars, W. Kant's Transcendental Idealism. In Proceedings of the Ottawa Congress on Kant, P. Laberge, F. Duchesneau, and B. E. Morrisey, Eds. University of Ottawa Press, I974, pp. I65-I8I. 
[28] Strawson, P. F. The Bounds of Sense: An Essay on Kant's Critique of Pure Reason. Methuen, I966.

[29] Vaininger, H. Zu Kants Widerlegung des Idealismus. In Straßburger Abhandlungen zur Philosophie. Akad. Verlagsbuchhandlung, I 884 , pp. $85-$ I 64 .

[30] van Cleve, J. Problems from Kant. Oxford University Press, I999. 